\title{
DELIVERING GIS TRAINING USING GEOSPATIAL WEB SERVICE - A CASE STUDY OF LANDSLIDE RISK MAPPING IN HONG KONG
}

\author{
J. Huang ${ }^{\text {a }}$, L. You ${ }^{\text {b, c, }}{ }^{*}$, Q. Zhou ${ }^{\text {a, b }}$, H. Wu ${ }^{b}$ \\ ${ }^{a}$ Department of Geography, Hong Kong Baptist University, Hong Kong, China - (jrhuang, qiming)@hkbu.edu.hk \\ ${ }^{\mathrm{b}}$ State Key Laboratory of Information Engineering in Surveying, Mapping and Remote Sensing, Wuhan University, Wuhan 430079, \\ China - wuhuayi@whu.edu.cn \\ ${ }^{c}$ Faculty of Computer Science and Information Engineering, Hubei University, Wuhan 430062, China \\ youlan2015@gmail.com
}

Commission VI, 1-3

KEY WORDS: Geospatial web service, Landslide

\begin{abstract}
:
This paper sketches a prototype of web-based landslide prediction service for delivering web-based training. The results show that the proposed landslide GWSC model can effectively compute the landslide risk level in different location, and consequently allow for early-warning, which starts with the sensor in the field and ending with user-opitmized warning messages and action advice.
\end{abstract}

\section{INTRODUCTION}

The advance of web technology has been rapidly changing Geographic Information Sciences (GIS). Web services and tools enable the sharing of geospatial data, developing of online geospatial model, and delivering web-based service. Geospatial web service (GWS) is a cross-language, cross-platform and cross-application web component which implements complex geo-computation processes. With the development of information interoperability and web services technologies, more and more GIS researchers publish the GWSs on the internet integrating their geoprocessing algorithm and geodata. By chaining these distributed GWSs, a geospatial web services composition (GWSC) model can be built including a series of geocomputation and analysis steps rather than a single geoprocess. This paper reports our latest effort to delivering a webbased landslide risk prediction training for decision-makers.

\section{LANDSLIDE DISASTER IN HONG KONG}

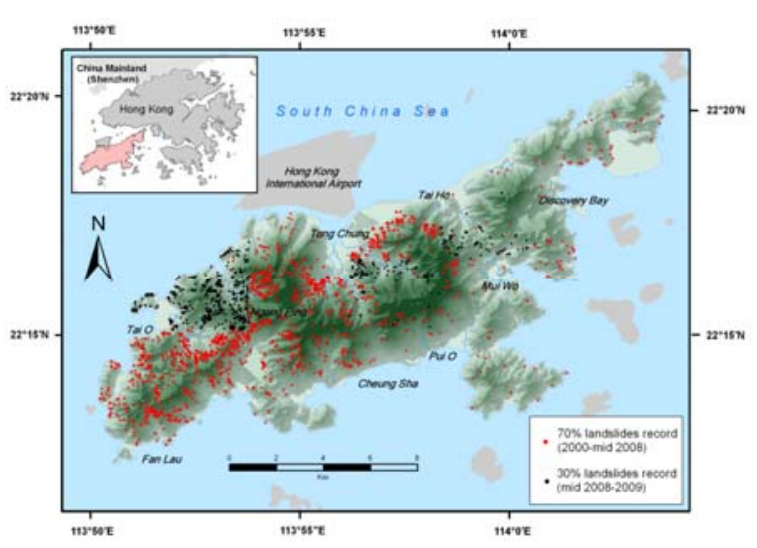

Figure 1. Study area and landslide inventory
Landslides are amongst the most damaging natural hazards in the hilly regions. The increasing awareness of socio-enonomic impacts as well as pressure of urbanization has facilitated the monitoring and analysis study. The mountainous terrain, heavy and prolonged rainfall and dense development near steep hillsides make Hong Kong as one of the most vulnerable metropolitans to the risk of landslides (Figure. 1) (Zhou et al. 2002). Therefore, regional-specific landslide susceptibility assessment in Hong Kong is necessary for hazard management and effective land use planning. On the other hand, building a geospatial web services composition (GWSC) model for landslide disaster prediction is benefit for the early warning and prevention works in advance.

\section{LANDSLIDE CAUSATIVE FACTORS}

The historical landslide points of 2000-2009 are derived from Enhanced Natural Terrain Landslide Inventory (ENTLI) (Figure. 1), developed from interpretation of $4000 \mathrm{ft}$ air photos in Hong Kong. The map Normalized Differences Vegetation Index (NDVI) is derived from Landsat TM image acquired at October, 2009. Other causative factors include: DEM and its derivatives (slope and aspect), lithology, distance to river and distance to fault. Frequency ratio method, based on the observed relationships between distribution of landslides and each landslide-related factor, is used to reveal the correlation between landslide location and the factors to evaluate the contribution of each factor.

\section{BULDING THE SERVICE MODEL}

According to the geo-process in landslide analysis, we propose a GWSC model which is composed by four GWS components: RasterToMatrix GWS, MatrixFileRead GWS, Frequency Ratio Analysis GWS and MatrixToRaster GWS. These four components are designed and implemented in standardized web

* Corresponding author 
services specification. This makes the GWS components easily chaining into a GWSC model in WS-BPEL specification and reusing in different landslide prediction applications.

The GWSC model receives a series of factors contributing to landslide and image data as the input data (Figure. 2). When finishing the geoprocessing, an image map with landslide dangerous point will be presented as the output results. In order to verify the landslide GWSC model, this study reports an experiment using the real terrain data in Hong Kong. The results show that the proposed landslide GWSC model can effectively compute the landslide risk level in different location, and consequently allow for early-warning, which starts with the sensor in the field and ending with user-opitmized warning messages and action advice.

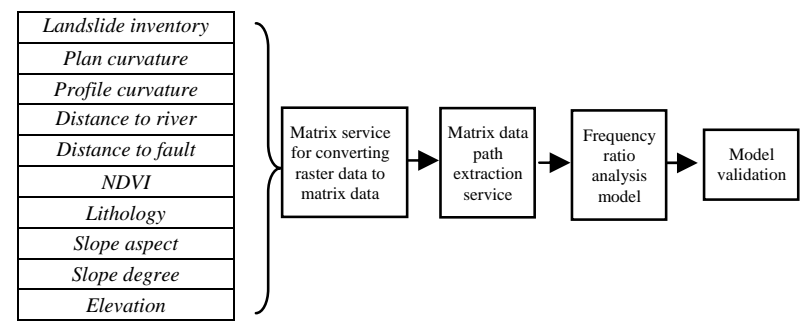

Figure 2. Building the training service model

\section{DISCUSSION}

This paper sketches a prototype of web-based landslide prediction service for delivering web-based training. Advances in information technology allow in situ ground and weather data to be transmitted to geospatial computation system so that a warning could be issued in a real-time and regional-specific manner (Yang et al. 2011). Further attempt can focus on developing the cloud-enabled real-time or near real-time landslide early warning service.

\section{ACKNOWLEDGEMENTS}

The research was supported by the Natural Science Foundation of China (NSFC) General Research Grant (41471340), Research Grants Council (RGC) of Hong Kong General Research Fund (GRF) (Project No. 203913) and Hong Kong Baptist University Faculty Research Grant (FRG1/12-13/070).

\section{REFERENCES}

Yang, C., Goodchild M., Huang, Q. 2011. Spatial Cloud Computing: How Can the Geospatial Sciences Use and Help Shape Cloud Computing? International Journal of Digital Earth, 4 (4): 305-329.

Zhou, C.H., Lee, C.F., Li, J. and Xu, Z.W. 2002. On the Spatial Relationship between Landslides and Causative Factors on Lantau Island, Hong Kong. Geomorphology, 43: 197-207. 